\title{
Standardization of in vitro Mass Multiplication Protocol for Gerbera cv. Partrizia
}

\author{
Shyama Kumari", Awdhesh Kumar Pal, Subhashish Sarkhel, \\ Paramveer Singh and Randhir Kumar
}

Bihar Agricultural College, BAU, Sabour-813210, Bhagalpur, Bihar, India

*Corresponding author

\section{A B S T R A C T}

Keywords

Gerbera,

Micropropagation, in

vitro regeneration,

Capitulum, Explant

Article Info

Accepted:

07 March 2018

Available Online:

10 April 2018
An effective protocol for in vitro proliferation and multiplication of Gerbera cv. Partrizia was established during 2015-17. Among the two stages initially used for culture initiation, capitulum explants cultured at immature stage responded better than the mature stage. Best establishment of immature capitulum explants and more number of quality shoots was obtained on modified MS medium supplemented with $10 \mathrm{mg} / \mathrm{l} \mathrm{BAP}$ and $1 \mathrm{mg} / \mathrm{l} \mathrm{IAA}$. Half strength MS medium containing NAA $(0.5 \mathrm{mg} / \mathrm{l})+\mathrm{IBA}(0.5 \mathrm{mg} / \mathrm{l})$ was best for root induction. The regenerated plantlets were efficiently hardened in glass jars filled with vermiculite + agropeat (1:2) moistened with half-strength MS medium salts and covered with polypropylene lids, thereafter plants were successfully transferred to the greenhouse with good survival. This protocol can produce 32,768 to $1,65,880$ vigorous, healthy and true to the type plants/year from a single capitulum.

\section{Introduction}

Gerbera, commonly known as African daisy, belongs to family Asteraceae and produces very attractive flowers. Gerbera produces flowers of commercial interest throughout the world covering a wide range of climatic conditions and it is widely used as a decorative and eye-catching garden plant or as cut flowers. Gerbera has great demand in the floral industry as cut flower as well as potted plant due to its beauty, colour and long vase life (Kanwar and Kumar, 2004). The nonavailability of noble quality planting material of commercially significance is a major limitation for its extensive cultivation in India.
Its commercial propagation through division of clumps and other conventional methods of propagation is slow, reluctant and insufficient for the production of large number of uniform propagules (Aswath and Choudhary, 2001). Micropropagation is the only sustainable alternative for extensive proliferation and multiplication of gerbera. This technique is free of seasonal bonds and facilitates manifold multiplication of the selected plants. An additional advantages are product uniformity, disease-free plants, easy exchange of germplasm as well as planting material. Moreover, this method provides base for application of different genetic improvement tools, viz. in vitro mutagenesis, in vitro 
selection, genetic transformation etc. The in vitro response in gerbera differs with cultivar, explants, and different proportion of media. Over the years gerbera is being propagated by direct or indirect organogenesis by means of various explants comprising stem tips, floral buds, leaf, capitulum etc. The plants are produced from explants of capitulum in red flower gerbera, leaves, floral buds, floral bracts and inflorescence. The benefits of the capitulum method over shoot tip are the easier sterile isolation in vitro. It is also nondestructive, simply inflorescences are used and no shoots are lost from the plant.

Hence, present investigation was undertaken to develop an efficient and economically feasible protocol for commercial mass multiplication of gerbera through capitulum explant.

\section{Materials and Methods}

The present study was carried out at the Tissue Culture Laboratory, Bihar Agricultural University, Sabour, Bhagalpur, Bihar during 2015-2017. Gerbera cultivar Partrizia maintained at the polyhouse complex, Department of Horticulture (Vegetable and Floriculture), Bihar Agricultural University, Sabour was used for this experiment. The capitulum explants were collected at two stages, i.e. at immature stage $(0.5$ to $1.0 \mathrm{~cm}$ diameter) and at mature stage $(1.5$ to $2.0 \mathrm{~cm}$ diameter). The exterior involucral bracts of the capitulum were detached and then it was sectioned into 4-8 pieces. The explants were wash-down with Teepol® $(0.1 \%)$ solution for5 min. followed by washing under running tap water for 15 min.to get rid of any residue of the detergent.

The explants were pre-treated with $0.1 \%$ Bavistin $₫($ Carbendazim $)+0.1 \%$ Ridomil $₫$ (Metalaxyl + Mancozeb) + $200 \mathrm{mg} / \mathrm{l}$ 8-HQC for three hours. The explants were surface sterilized with $0.1 \%$ mercuric chloride for 5 min. so as to reduce culture contamination. Surface sterilized explants were given 4-6 washings with sterile double-distilled water to take out the traces of sterilizing agent(s) directly after treatment. The explants were inoculated on basal Murashige and Skoog (1962) medium containing $1 \mathrm{mg} / \mathrm{l}$ Thiamine$\mathrm{HCl}, 5 \mathrm{mg} / \mathrm{l}$, Pyridoxine-HCl and $5 \mathrm{mg} / \mathrm{l}$ Nicotinic acid i.e. modified MS medium.

The surface sterilized explants were cultured on modified MS medium added with different concentrations of BAP (2.0, 5.0 and 7.0 and $10 \mathrm{mg} / \mathrm{l})$ and IAA $(1 \mathrm{mg} / \mathrm{l})$ to find out the best treatment combination for culture establishment as well as shoot multiplication. Medium devoid of any hormone served as control. The $\mathrm{pH}$ of the medium was regulated to 5.7 to 5.8 with drop-wise addition of $1 \mathrm{~N}$ $\mathrm{KOH}$ or $1 \mathrm{~N} \mathrm{HCl}$ via a digital $\mathrm{pH}$ meter. The contents were then sterilized in a vertical autoclave at $121^{\circ} \mathrm{C}$ for 20 minutes (15 $\left.\mathrm{lbs} / \mathrm{inch}^{2}\right)$. The cultures were maintained at $25 \pm 1^{\circ} \mathrm{C}$ under fluorescent white light (47 $\mathrm{mol} / \mathrm{m}^{2} / \mathrm{s}$ ) at a photoperiod of $16: 8$ hours light and dark cycles.

The multiplied shoots on proliferation media were isolated and single micro-shoots were transferred on elongation media containing basal MS medium supplemented with different concentration of $\mathrm{GA}_{3}(0.25,0.5$ and $1.0 \mathrm{mg} / \mathrm{l})$ to standardize its optimal dose for micro-shoots elongation. Elongated shoots were then transferred individually in cultured vessels containing half-strength of MS medium fortified with different concentrations of auxins like NAA and IBA individually or in combination for rooting.

A dose of7 g/l of Agar plus30 g/l of sucrose was added for culture establishment as well as for shoot proliferation and $7 \mathrm{~g} / \mathrm{l}$ of Agar with $50 \mathrm{~g} / \mathrm{l}$ was added in rooting medium. The in vitro rooted plantlets were taken out from 
flasks, washed thoroughly using autoclaved distilled water to eliminate the sticking agaragar to roots. The roots were then dipped in carbendazim $(0.1 \%)$ for $10 \mathrm{~min}$. The plantlets were then acclimatized in glass jars filled with vermiculite + agro peat (1:2) moistened with half-strength MS medium salts (macro+ micro) and shielded with polypropylene lids. The data were analysed using completely randomized design (CRD) and percent data was subjected to ArcSin $\sqrt{ } \%$ transformation before ANOVA.

\section{Results and Discussion}

\section{Effect of explants and media on culture establishment as well as shoot proliferation}

The morphological potential in gerbera varied with the developmental stage of explant. Among the two stages, capitulum explant cultured at immature stage responded better than the mature stage (Table 1; Fig. 1a). At immature stage, $46.14 \%$ explants established, whereas in mature capitulum only $10.00 \%$ of explants responded. Shoot emergence was observed after 57.40 days and 65.94 days in immature and mature capitulum, respectively. The number of sprouted shoots per explants was also higher (9.00) in immature capitulum as compared to mature capitulum (1.14) considerably.

Type of explant, stage, growth, biochemical composition, coupled with the presence of phytohormones, their ratio and level etc. decide the in vitro behaviour of explants. Schum and Busold (1985) also reported quicker and higher in vitro shoot production from immature floral buds than that of fully developed inflorescences in gerbera. When development pattern was considered, two explants performed differently. In immature capitulum, initially no significant variation in the morphology of the floral bud was detected except for loosening of florets and drying of outer involucral bracts. Consequently, growth of florets was perceived in the form of swelling and greening of the florets. Later, shoot development occurred directly from these florets. This might be due to the formation of meristematic tissues in segment of immature flower heads (Mandal et al., 2002). The mature capitulum showed normal floral development with the formation of ray and disc florets. Later on the ray and disc florets dried completely and the explant turned brown. In few explants, shoot emergence was seen on the completely dried explant from the base of the receptacles. Schum and Busold (1985) also observed shoot development in the axils of involucral bracts of immature floral buds, whereas shoots developed from undifferentiated calli in completely matured inflorescence.

The induction media had major effect on initial culture establishment as well as shoot proliferation from capitulum explant (Table 1; Fig. 1a). The capitulum explants failed to establish on medium without growth regulators. On the other hand, significant improvement in culture establishment was observed with the addition of growth regulators to the media. Medium containing $10 \mathrm{mg} / \mathrm{l} \mathrm{BAP}$ and $1 \mathrm{mg} / \mathrm{l}$ IAA was optimum for initial establishment. On this media shoot emergence was observed after 74.51 days of culturing. The number of shoots per explant was also maximum (10.51) on this media. With the increase in level of BAP, significant decline in days to sprout and an increase in the sprouted shoot were noticed. The role of auxins and cytokinin in micropropagation is well known and the best morphogenetic response can be achieved from synergistic effect of compatible auxins and cytokinin combination (Aswath and Choudhary, 2001). The encouraging effect of cytokinins on shoot meristem initiation, axillary bud bursting as well as multiple shoot production have been demonstrated by Pierik et al., (1975). 
Table.1 Effect of explants and induction media on culture establishment and shoot proliferation in gerbera cv. Partrizia

\begin{tabular}{|c|c|c|c|c|c|c|c|c|c|}
\hline & \multicolumn{3}{|c|}{ Culture establishment (\%) } & \multicolumn{3}{|c|}{ Days to shoot emergence } & \multicolumn{3}{|c|}{ No. of shoots per explant } \\
\hline Media & $\mathrm{IC}$ & $\mathrm{MC}$ & Mean & $\mathrm{IC}$ & $\mathrm{MC}$ & Mean & IC & $\mathrm{MC}$ & Mean \\
\hline $\begin{array}{l}\text { MS* devoid of } \\
\text { hormone (Control) }\end{array}$ & 0 & 0 & 0 & 0 & 0 & 0 & 0 & 0 & 0 \\
\hline $\begin{array}{l}\text { MS* + BAP (2 mg/l) } \\
+ \text { IAA (1 mg/l) } \\
\end{array}$ & $\begin{array}{c}16.67 \\
(24.08)\end{array}$ & 0 & 8.34 & 103.34 & 0 & 51.67 & 2.34 & 0 & 1.17 \\
\hline $\begin{array}{l}\text { MS* + BAP (5 mg/l) } \\
+ \text { IAA (1 mg/l) }\end{array}$ & $\begin{array}{c}60.00 \\
(50.77)\end{array}$ & $\begin{array}{c}8.34 \\
(16.77)\end{array}$ & 34.17 & 75.33 & 121.34 & 98.34 & 9.67 & 1.34 & 5.51 \\
\hline $\begin{array}{l}\text { MS* + BAP (7 mg/l) } \\
+\mathrm{IAA}(1 \mathrm{mg} / \mathrm{l}) \\
\end{array}$ & $\begin{array}{c}71.67 \\
(57.85)\end{array}$ & $\begin{array}{c}15 \\
(22.76)\end{array}$ & 43.34 & 61 & 106.67 & 83.84 & 14.67 & 1.67 & 8.17 \\
\hline $\begin{array}{l}\text { MS* + BAP }(10 \\
\text { mg/l) + IAA (1 mg/l) }\end{array}$ & $\begin{array}{c}82.34 \\
(65.17)\end{array}$ & $\begin{array}{c}26.67 \\
(31.09)\end{array}$ & 54.51 & 47.34 & 101.67 & 74.51 & 18.34 & 2.67 & 10.51 \\
\hline Mean & 46.14 & 10.00 & & 57.40 & 65.94 & & 9.00 & 1.14 & \\
\hline $\operatorname{SEm}( \pm)$ & 0.61 & 0.59 & & 0.99 & 1.77 & & 0.50 & 0.19 & \\
\hline $\mathrm{CD}(0.05)$ & 1.94 & 1.88 & & 3.17 & 5.64 & & 1.61 & 0.61 & \\
\hline
\end{tabular}

* Modified MS

Table.2 Effect of $\mathrm{GA}_{3}$ on shoot elongation in gerbera cv. Partrizia

\begin{tabular}{|l|l|}
\hline Treatments & $\begin{array}{l}\text { Length of shoots } \\
(\mathrm{cm})\end{array}$ \\
\hline MS devoid of $\mathrm{GA}_{3}$ (Control) & 2.34 \\
\hline $\mathrm{MS}+\mathrm{GA}_{3}(0.25 \mathrm{mg} / \mathrm{l})$ & 3.16 \\
\hline $\mathrm{MS}+\mathrm{GA}_{3}(0.5 \mathrm{mg} / \mathrm{l})$ & 4.57 \\
\hline $\mathrm{MS}+\mathrm{GA}_{3}(1.0 \mathrm{mg} / \mathrm{l})$ & 7.34 \\
\hline $\mathrm{SEm}( \pm)$ & 0.59 \\
\hline $\mathrm{CD}(\mathbf{0 . 0 5})$ & 1.96 \\
\hline
\end{tabular}

Table.3 Effect of IBA and NAA on rooting induction in gerbera cv. Partrizia

\begin{tabular}{|c|c|c|c|c|}
\hline Treatments & Rooting (\%) & $\begin{array}{l}\text { Days to root } \\
\text { initiation }\end{array}$ & $\begin{array}{l}\text { No.of roots per } \\
\text { microshoots }\end{array}$ & $\begin{array}{l}\text { Root length } \\
(\mathrm{cm})\end{array}$ \\
\hline 1/2 MS devoid of auxins (Control) & $\begin{array}{l}16.34 \\
(23.83)\end{array}$ & 33.34 & 1.67 & 2.08 \\
\hline 1/2 MS + NAA (0.5 mg/l) & $\begin{array}{l}93.34 \\
(75.28)\end{array}$ & 17.67 & 3.67 & 4.76 \\
\hline 1/2 MS + IBA (0.5 mg/l) & $\begin{array}{l}96.67 \\
(79.82)\end{array}$ & 13.34 & 5.34 & 6.2 \\
\hline 1/2 MS + NAA $(0.5$ mg/l) + IBA (0.5 mg/l) & $\begin{array}{l}98 \\
(81.95)\end{array}$ & 11.34 & 8.67 & 5.69 \\
\hline 1/2 MS + NAA (1.0 mg/l) + IBA (1.0 mg/l) & $\begin{array}{l}91.67 \\
(73.28)\end{array}$ & 18.34 & 6.34 & 4.61 \\
\hline SEm( \pm ( & 1.40 & 0.96 & 0.54 & 0.72 \\
\hline CD (0.05) & 4.48 & 3.05 & 1.72 & 2.30 \\
\hline
\end{tabular}

Table.4 Effect of various hardening strategies on acclimatization of in vitro raised plantlets of gerbera

\begin{tabular}{l} 
Treatments \\
Glass Jars with polypropylene \\
caps \\
\hline Plastic pots with polythene \\
covers \\
\hline SEm $( \pm)$ \\
\hline CD $(0.05)$
\end{tabular}

\begin{tabular}{|l|l|}
\hline Survival \% & Number of leaves /plant \\
\hline 89.67 & 7.67 \\
\hline 67.67 & 5.67 \\
\hline 4.04 & 0.78 \\
\hline 16.27 & NS \\
\hline
\end{tabular}


Fig.1 In Vitro plant regeneration in Gerbera cv. Partrizia. (a) Shoot Proliferation. (b) Shoot elongation. (c) In vitro rooting. (d) Rooted plants ready to transfer. (e) well established harden plants ready for polyhouse planting (f) well established gerbera plants at polyhouse

(g) Gerbera plants at flowering

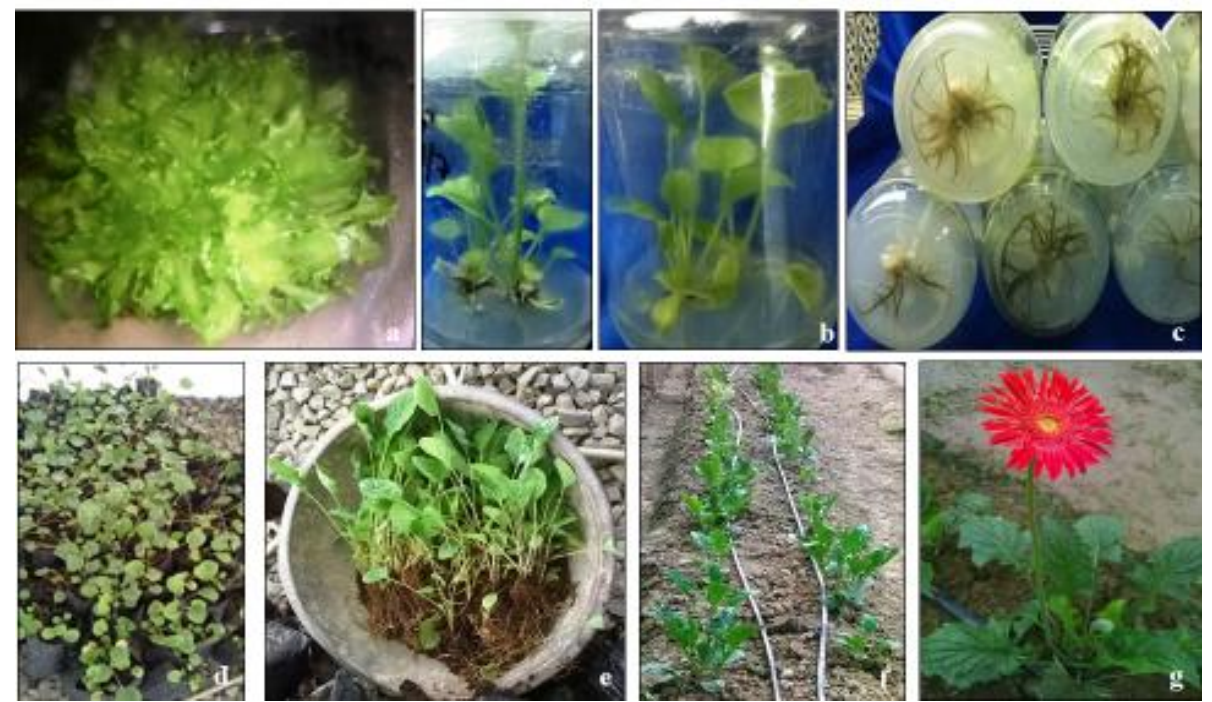

\section{In vitro shoot length enhancement}

The data presented in Table 2 and Figure $1 b$ revealed significant difference in shoot length among the various media used. Maximum shoot length $(7.34 \mathrm{~cm})$ was on MS media supplemented with $1 \mathrm{mg} / \mathrm{l} \mathrm{GA}$ which was significantly higher than MS media supplemented with $0.5 \mathrm{mg} / \mathrm{l}$ i.e. $4.57 \mathrm{~cm}$. The minimum shoot length $(2.34 \mathrm{~cm})$ was recorded on control.

\section{In vitro root induction}

Application of half strength MS medium with either of NAA or IBA had an 7intense effect on inducing early rooting (Table 3; Fig. 1c). The shoots cultured on medium without of rooting hormone showed meagre rooting $(16.34 \%)$ and took maximum time (33.34 days) to root initiation. Rooting was significantly enhanced with the addition of auxins into the media. Half strength MS medium containing $0.5 \mathrm{mg} / \mathrm{l}$ IBA plus 0.5 $\mathrm{mg} / \mathrm{l}$ NAA was optimal for root induction. On this medium root initiation occurred at the earliest (11.34 days). The longest roots (5.69 $\mathrm{cm}$ ) with noble root growth were also noted on this medium. The root formation is significantly influenced by the presence of auxins and sugars, however presence and absence of macro-elements did not influence rooting (Pierik et al., 1975).

\section{Acclimatization of in vitro raised plants}

Out of the two in vitro hardening strategies, better hardening was observed in glass jars with polypropylene cap (Table 4). The per cent survival during hardening in glass jars with polypropylene caps was 89.67 per cent. Whereas, only 67.67 per cent of plants survived when hardening was done in plastic pots covered with polythene cover. High mortality due to desiccation and contamination was observed during hardening in plastic pots covered with polythene covers. This high success in glass jar might be due to high moisture retention and also due to constant maintenance of relative humidity (RH) level compared to other strategies. 
Multiplication potential of the developed protocol

A single multiplication cycle in gerbera from proliferation to acclimatization is of 10-12 weeks. Therefore, around four multiplication cycles are possible per year. Taking an average of 10 healthy shoots regenerated from a single capitulum explant at establishment stage; as high as 32,768 to $1,65,880$ healthy, true-to-the-type plants can be produced per year from a single capitulum.

\section{Acknowledgements}

The authors acknowledge the Directorate of Research, BAU, Sabour for providing financial support and incharge, Tissue Culture Lab, BAU, Sabour for providing lab facilities.

\section{References}

Aswath C and Choudhary M L. 2001. Effect of cytokinins on proliferation of multiple shoots in gerbera (Gerbera jamesonii). Indian Journal of Horticulture 58: 383-6.

Kumar S, Kanwar J K and Sharma D R. 2004. In vitro regeneration of Gerbera jamesonii Bolus from leaf and petiole explants. Journal of Plant Biochemistry and Biotechnology 13: 73-5.

Mandal A K A, Saxena M, Datta S K. 2002. Acclimatization of gerbera at Lucknow after in vitro multiplication. Indian Journal of Genetics and Plant Breeding 62 (4): 375-6.

Murashige, T. and Skoog F. (1962). A revised medium for rapid growth and bioassays with tobacco tissue cultures. Physiol. Plant, 15: 373-397

Pierik, R.L.M., Jansen J.L.M., Maasdam A. and Binnendijk, C.M. (1975). Optimization of gerbera plantlet production from excised capitulum explants. Scientia Hort. 3 (4): 351-57

Schum, A. and Busold, M. (1985). In vitro shoot production from inflorescences of gerbera. Gb-t-Gw., 85 (47): 1744-1746

\section{How to cite this article:}

Shyama Kumari, Awdhesh Kumar Pal, Subhashish Sarkhel, Paramveer Singh and Randhir Kumar. 2018. Standardization of in vitro Mass Multiplication Protocol for Gerbera cv. Partrizia. Int.J.Curr.Microbiol.App.Sci. 7(04): 514-519.

doi: https://doi.org/10.20546/ijcmas.2018.704.060 